\title{
Adalimumab therapy reduces hand bone loss in early rheumatoid arthritis: explorative analyses from the PREMIER study
}

\author{
M Hoff,, ${ }^{1,2}$ T K Kvien, ${ }^{3,4}$ J Kälvesten, ${ }^{5}$ A Elden, ${ }^{6}$ G Haugeberg ${ }^{2,7}$
}

\begin{abstract}
- An additional table is published online only at http:// ard.bmi.com/content/vol68/ issue7

${ }^{1}$ Department of Rheumatology, St Olav's Hospital, Trondheim, Norway; ${ }^{2}$ Norwegian University of Science and Technology, Trondheim, Norway;

${ }^{3}$ Department of Rheumatology, Diakonhjemmet Hospital, Oslo, Norway: ${ }^{4}$ Faculty of Medicine, University of Oslo, Oslo, Norway; ${ }^{5}$ Sectra, Linköping, Sweden;

${ }^{6}$ Abbott Laboratories, Oslo,

Norway; ${ }^{7}$ Department of

Rheumatology, Sørlandet

Hospital, Kristiansand S, Norway
\end{abstract}

Correspondence to:

Dr M Hoff, University Hospital of

Trondheim, Norwegian

University of Science and

Technology, MTFS, Department

of Neuroscience, Division of

Rheumatology, N0-7489

Trondheim, Norway;

mari.hoff@ntnu.no

Accepted 6 September 2008

Published Online First

16 September 2008

\begin{abstract}
Objective: The effect of adalimumab on hand osteoporosis was examined and related to radiographic joint damage in the three treatment arms of the PREMIER study: adalimumab plus methotrexate, adalimumab and methotrexate monotherapy. Predictors of hand bone loss were also searched for.

Methods: 768 patients (537 fulfilled 2 years) with rheumatoid arthritis (RA) for less than 3 years, never treated with methotrexate, were included. Hand bone loss was assessed by digital $x$ ray radiogrammetry (DXR) on the same hand radiographs scored with modified Sharp score at baseline, 26, 52 and 104 weeks. For DXR, metacarpal cortical index (MCI) was the primary bone measure.
\end{abstract}

Results: At all time points the rate of percentage DXR$\mathrm{MCl}$ loss was lowest in the combination group $(-1.15$; $-2.16 ;-3.03)$ and greatest in the methotrexate monotherapy group $(-1.42 ;-2.87 ;-4.62)$, with figures in between for the adalimumab monotherapy group $(-1.33 ;-2.45 ;-4.03)$. Significant differences between the combination group and the methotrexate group were seen at $52(p=0.009)$ and 104 weeks $(p<0.001)$. The order of hand bone loss across the three treatment arms was similar to the order of radiographic progression. Older age, elevated C-reactive protein and non-use of adalimumab were predictors of hand bone loss.

Conclusion: This study supports a similar pathogenic mechanism for hand bone loss and erosions in RA. The combination of adalimumab and methotrexate seems to arrest hand bone loss less effectively than radiographic joint damage. Quantitative measures of osteoporosis may thus be a more sensitive tool for assessment of inflammatory bone involvement in RA.

In rheumatoid arthritis (RA), bone damage on radiographs presents not only as erosions but also as periarticular osteoporosis. ${ }^{1}$ Hand bone loss in early RA has been shown to occur more rapidly than bone loss at the hip and spine $e^{2-4}$ and also predicts radiographic joint damage. ${ }^{5}$

Inflammatory activation of the osteoclast is involved in both features. Studies support that cytokines, eg, tumour necrosis factor (TNF) alpha, macrophage colony-stimulating factor and receptor activator of nuclear factor kappa ligand (RANKL), activate the osteoclast that causes osteoporosis (localised and generalised) and erosions..$^{6-8}$

Anti-TNF therapy has been shown to reduce the progression of radiographic joint damage significantly in RA patients. ${ }^{9-11}$ A few studies have also suggested that anti-TNF therapy may prevent general bone loss. ${ }^{12-14}$
Quantitative hand bone measures have been recommended for their sensitivity to assess inflammatory bone involvement in early RA. ${ }^{15}$ However, only a few studies have examined the effect of antiinflammatory treatment (including anti-TNF therapy) on hand bone loss in RA. ${ }^{41} 1617$ Furthermore, only one randomised controlled trial has been conducted in which the anti-inflammatory effects of prednisolone $(7.5 \mathrm{mg}$ daily) compared with placebo were shown to reduce significantly not only the rate of radiographic joint damage, but also the rate of hand bone loss. ${ }^{17}$

The primary objective of this analysis was to examine cortical hand bone loss in the three arms of the PREMIER study: adalimumab plus methotrexate versus adalimumab monotherapy versus methotrexate monotherapy and to evaluate associations between hand bone loss and radiographic progression. Our second objective was to identify potential predictors of hand bone loss.

\section{METHODS}

\section{Study sample and design}

The radiographic and clinical data from this 2-year, multicentre, double-blind, randomised controlled study (PREMIER) have previously been described in detail. ${ }^{11}$ In short, the efficacy and safety of adalimumab plus methotrexate was compared with adalimumab monotherapy and with methotrexate monotherapy in 799 adult patients with early ( $<3$ years, mean disease duration 9.1 months), aggressive RA (inclusion criteria: $\geqslant 8$ swollen joints; erythrocyte sedimentation rate $\geqslant 28$ or C-reactive protein $(\mathrm{CRP}) \geqslant 1.5 \mathrm{mg} / \mathrm{dl}$; erosions or rheumatoid factor positive), who previously had not been treated with methotrexate, cyclophosphamide, cyclosporine, azathioprine or more than two other disease-modifying antirheumatic drugs (DMARD) (table 1). ${ }^{11}$ The combination group received adalimumab $40 \mathrm{mg}$ subcutaneously every other week plus weekly methotrexate by mouth (rapidly increased to $20 \mathrm{mg} /$ week), and the monotherapy groups received either adalimumab $40 \mathrm{mg}$ subcutaneously every other week plus placebo or weekly methotrexate by mouth plus placebo. Radiographs from hands and feet were scored according to the modified Sharp score (range 0398). ${ }^{11}$

From this study, we present hand bone loss data at 26, 52 and 104 weeks of follow-up. To maintain the original study design of a blinded randomised controlled trial, the treatment code was kept secret for one of the authors who analysed the data $(\mathrm{MH})$. 


\section{DXR hand bone measure}

Digital $x$ ray radiogrammetry (DXR; Sectra, Linköping, Sweden) was used to measure hand bone mineral density (BMD) and the metacarpal cortical index (MCI) on the same digitised hand $x$ rays used for the assessment of radiographic joint damage. DXR is a computer version of the traditional radiogrammetry technique $e^{18}$ and the method has previously been described in detail. ${ }^{19-21}$ On hand radiographs, the computer automatically recognises regions of interest around the narrowest part of the second, third and fourth metacarpal bone and measures cortical thickness, bone width and porosity 118 times per centimetre. $\mathrm{DXR}-\mathrm{BMD}$ is defined as: $c \times \mathrm{VPA}_{\mathrm{comb}} \times(1-p)$, where $c$ is a density constant, VPA is volume per area and $p$ is porosity. DXR-MCI is defined as the combined cortical thickness divided by the bone width and is a relative bone measure independent of bone size and bone length. ${ }^{21}{ }^{22}$ In the literature short-time invivo precision (CV\%) has been reported to range from $0.28 \%$ to $0.59 \%$ for DXR-BMD and from $0.31 \%$ to $0.64 \%$ for DXRMCI. ${ }^{19} 2123$

DXR-BMD was intended to be the main outcome measure in this study. However, many radiographs could not be analysed for $\mathrm{BMD}$ because of unknown image resolution. The equation for DXR-BMD is based on volume per area and requires a known resolution, because a distance in a digitised radiograph cannot be measured when the resolution is unknown. Therefore, DXR-MCI, which is a relative measure less dependent on image resolution, was used as the primary outcome measure. The correlation between DXR-BMD and DXR-MCI has been shown to be substantial $(r>0.90)$, both cross-sectionally ${ }^{24}$ and longitudinally. ${ }^{25}$

For comparison, we also present results for DXR-BMD. All images with unknown resolution were analysed by assuming $254 \mathrm{dpi}$ (the scanning resolution for the radiographs before scoring). Several of the radiographs were, however, clearly of a resolution other than $254 \mathrm{dpi}$, most likely because these radiographs had been printed in non-true size before scanning. We analysed all available images for DXR-BMD at baseline, as well as 26, 52 and 104 weeks and calculated DXR width. Based on analyses from studies with a controlled resolution, ${ }^{25}$ a deviation from baseline width greater than $2 \%$ was likely to indicate an incorrect value. By using this $2 \%$ value as a cut-off, $23 \%$ of the radiographs were excluded from further DXR-BMD analyses. The flow chart in fig 1 illustrates the patients who were included in the DXR-MCI and DXR-BMD analyses.

To avoid bias regarding dominant and non-dominant hand and to achieve better precision, we employed mean value measurements from both hands. ${ }^{15}$ If the radiograph from one hand could not be analysed, we used the radiograph from the available hand for all analyses at all time points.

The radiographs were acquired by a single emulsion mammography film; film focus distance $100 \mathrm{~cm}$; tube voltage $50-55 \mathrm{kV}$ according to the radiographic equipment and the exposure dose was $8 \mathrm{mAs}$.

\section{Statistical analysis}

As the data were skewed, non-parametric analyses were conducted. No imputations were performed. Baseline values were compared between treatment groups with the KruskallWallis method for continuous variables and the $\chi^{2}$ method for categorical variables. Comparisons of changes in DXR were conducted using methodologies employed in the original PREMIER study. ${ }^{11}$ Two groups were compared in a hierarchical order with the Mann-Whitney U test, ie, two-sided comparison of the combination group versus methotrexate, followed by two-sided comparisons between the adalimumab monotherapy and methotrexate monotherapy treatment arms and finally two-sided comparisons between the adalimumab monotherapy and the combination group. Each pair-wise comparison was completed only if the previous comparison was statistically significant. Bone loss over time was expressed as a negative value.

A linear regression model was developed to search for predictors of hand BMD loss at 26, 52 and 104 weeks.

Table 1 Baseline characteristics for early RA patients in PREMIER*

\begin{tabular}{|c|c|c|c|}
\hline & $\begin{array}{l}\text { Adalimumab + } \\
\text { methotrexate } \\
\text { (N = 261) }\end{array}$ & $\begin{array}{l}\text { Adalimumab } \\
\text { monotherapy } \\
\text { (N = 261) }\end{array}$ & $\begin{array}{l}\text { Methotrexate } \\
\text { monotherapy } \\
\text { (N = 246) }\end{array}$ \\
\hline \multicolumn{4}{|l|}{ Demographic characteristics } \\
\hline Age, years & $52.2(13.8)$ & $51.9(13.7)$ & $51.9(13.3)$ \\
\hline Female, no (\%) & $187(71.6)$ & $205(78.5)$ & $181(73.6)$ \\
\hline \multicolumn{4}{|l|}{ Clinical characteristics } \\
\hline Disease duration, years & $0.7(0.8)$ & $0.7(0.8)$ & $0.8(0.9)$ \\
\hline Previously taken DMARD, no (\%) & $84(32.2)$ & $87(33.3)$ & $78(31.7)$ \\
\hline Previously taken corticosteroids, no (\%) & $92(35.2)$ & $94(36.0)$ & $85(34.6)$ \\
\hline Tender joint count, 0-66 & $31.1(14.1)$ & $31.7(13.5)$ & $32.2(14.3)$ \\
\hline Swollen joint count, $0-66$ & $21.2(11.1)$ & $21.7(10.2)$ & $21.6(11.3)$ \\
\hline C-reactive protein, mg/l & $39.5(42.4)$ & $40.7(38.6)$ & $40.6(41.2)$ \\
\hline $\mathrm{HAO}, 0-3$ & $1.5(0.6)$ & $1.6(0.6) \dagger$ & $1.5(0.7)$ \\
\hline DAS28 & $6.3(0.9)$ & $6.4(0.9)$ & $6.3(0.9)$ \\
\hline \multicolumn{4}{|l|}{ Image analysis } \\
\hline \multicolumn{4}{|l|}{ Modified TSS } \\
\hline Mean & $18.1(20.3)$ & $18.4(18.2)$ & $21.5(21.8)$ \\
\hline Median (25-75th percentile) & $12.8(6.0-24.0)$ & $13.5(5.1-25.5)$ & $15.5(7.5-28.5)$ \\
\hline DXR-MCI & $0.45(0.09)$ & $0.45(0.09)$ & $0.46(0.08)$ \\
\hline DXR-BMD， g/cm² & $0.57(0.08)$ & $0.57(0.08)$ & $0.58(0.08)$ \\
\hline
\end{tabular}




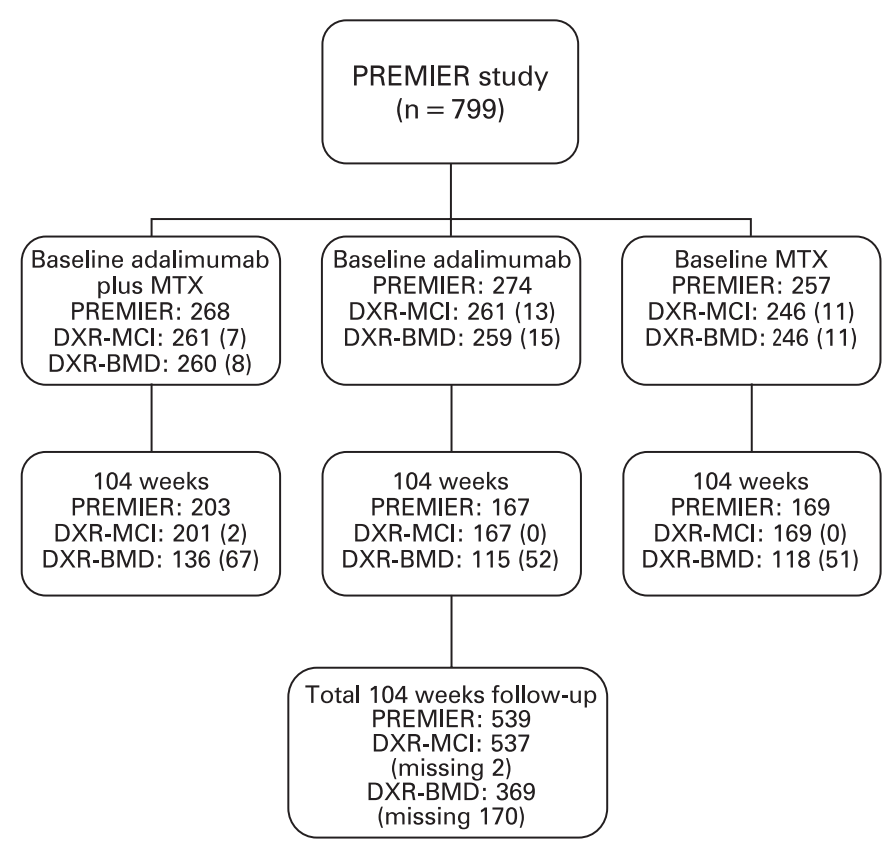

Figure 1 Flow chart of the examined patients with early rheumatoid arthritis in the present analysis. Numbers of missing $x$ rays compared with the original PREMIER study are provided in parentheses. BMD, bone mineral density; DXR, digital $x$ ray radiogrammetry; $\mathrm{MCl}$, metacarpal cortical index; MTX, methotrexate.

Spearman correlation analyses were conducted in an attempt to correlate changes in DXR-MCI with the following baseline variables: disease duration; disease activity measured by 28 -joint disease activity score (DAS28); ${ }^{26} \mathrm{CRP}$; disability index of health assessment questionnaire (HAQ) scores; $^{27}$ previous use of DMARD and cortisone; radiographic joint damage; randomised treatment arm and absolute DXR-MCI value. The variables with a $p$ value less than 0.15 were included in the multivariate model, which was also adjusted for age and gender. Treatment arm was coded as a dummy variable (methotrexate as 0 , adalimumab as 1 and combination group as 2).

The PREMIER study was approved by a central institutional review board and independent ethics committees at each participating site. ${ }^{11}$

\section{RESULTS}

Baseline DXR-MCI values were available for 768 of the 799 patients enrolled in the PREMIER study and DXR-MCI values were missing for two of 539 patients who completed the study (fig 1). The corresponding numbers for available DXR-BMD data (based on the cut-off values for image resolution described in the Methods section) were 765 and 369, respectively (fig 1). Demographics and baseline clinical characteristics for the whole group were comparable between the three treatment arms (table 1).

The only statistically significant difference between treatment arms was a slightly greater mean HAQ score for the adalimumab monotherapy group. Before enrollment, corticosteroids had been used in 35\% of the patients (mean daily dosage of prednisolone was $6.6 \mathrm{mg}$ ) and $32 \%$ had been treated with traditional DMARD other than methotrexate. The baseline radiographic damage scores were similar across treatment groups, with a median (mean) Sharp score of 14.0 (19.3) (table 1).
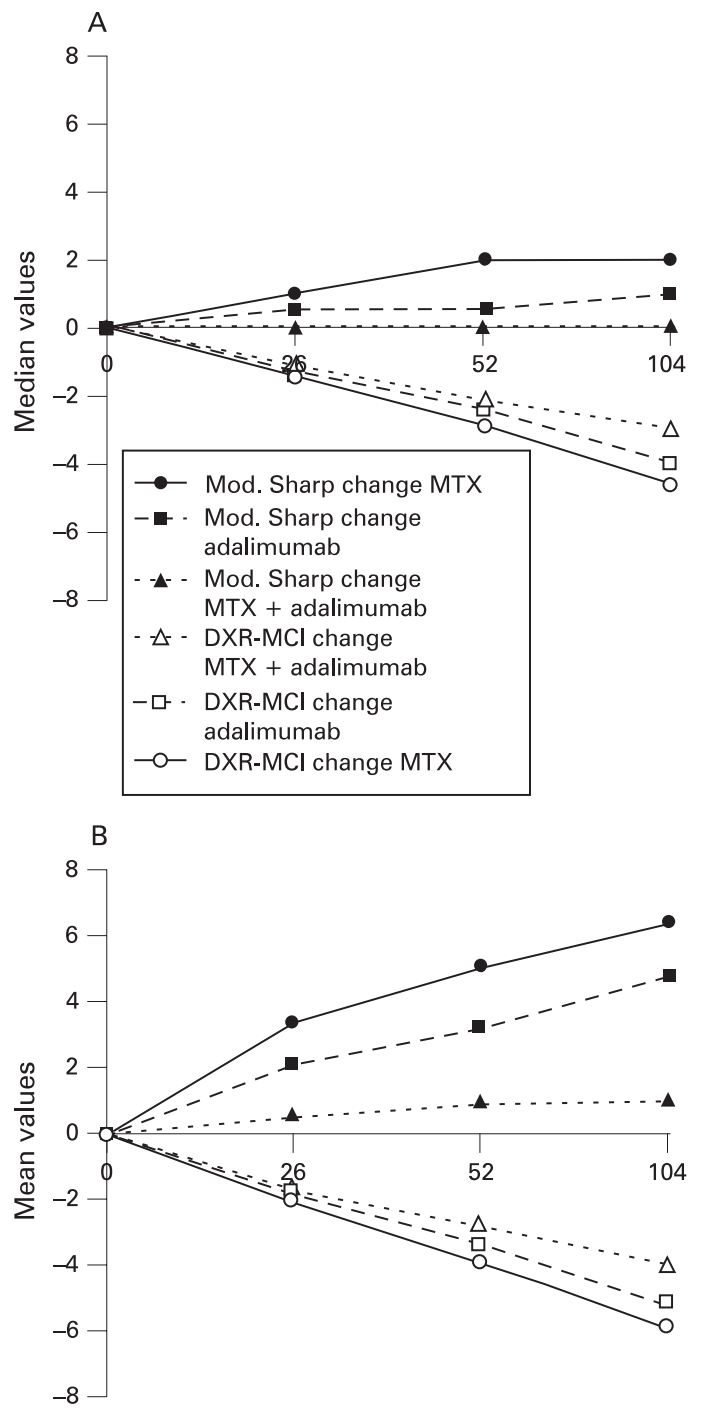

Figure 2 Changes in DXR-MCI (percentage) and modified Sharp score (units) over time in the three treatment groups of PREMIER ( $A$, median values; $\mathrm{B}$, mean values). DXR, digital $x$ ray radiogrammetry; $\mathrm{MCl}$, metacarpal cortical index; Mod Sharp, modified total Sharp score; MTX, methotrexate.

Median percentage DXR-MCI changes for all patients were $-1.29,-2.45$ and -3.72 at 26,52 and 104 weeks. Corresponding values for DXR-BMD were $-1.07 \%,-1.72 \%$ and $-2.63 \%$. Changes from baseline in DXR-MCI and DXR$\mathrm{BMD}$ were significant for all subgroups at all time points during follow-up $(p<0.001$ for all). The use of corticosteroids or DMARD did not affect hand bone loss (data not shown).

Correlation coefficients ( $r$ ) between the DXR-MCI and the DXR-BMD changes were 0.88, 0.93 and 0.94 at 26, 52 and 104 weeks $(p<0.001$ for all).

\section{DXR-MCI changes between treatment arms}

At 26, 52 and 104 weeks follow-up median percentage DXRMCI changes were $-1.15,-2.16$ and -3.03 for the adalimumab plus methotrexate combination group, $-1.33,-2.45$ and -4.03 for the adalimumab monotherapy group and $-1.42,-2.87$ and -4.62 for the methotrexate monotherapy group (fig 2).

The rate of DXR-MCI loss was significantly greater for the methotrexate group compared with the combination group at 
Table 2 Predictors for percentage DXR-MCl loss at 104 weeks followup in 515 RA patients explored by a multivariate linear regression model

\begin{tabular}{lcc}
\hline & \multicolumn{2}{c}{ DXR-MCl percentage change at 104 weeks } \\
\cline { 2 - 3 } & Beta & p Value \\
\hline Age, years & -0.25 & $<0.001$ \\
Female gender & -0.04 & 0.36 \\
Disease duration, years & 0.06 & 0.11 \\
C-reactive protein, mg/l & -0.23 & $<0.001$ \\
DAS28 & -0.09 & 0.07 \\
Treatment group* & 0.16 & $<0.001$ \\
$\mathrm{R}^{2}$, adjusted & 0.19 &
\end{tabular}

*Treatment groups coded as a dummy variable: 0 , methotrexate; 1, adalimumab; 2 , adalimumab plus methotrexate. $\mathrm{MCI}$ baseline, Sharp score baseline and $\mathrm{HAO}$ did not influence the model. DAS28, 28-joint disease activity score; DXR, digital $x$ ray radiogrammetry; $\mathrm{HAQ}$, health assessment questionnaire; $\mathrm{MCl}$, metacarpal cortical index; RA, rheumatoid arthritis.

52 weeks $(p=0.009)$ and 104 weeks $(p<0.001)$ and the same trend was also observed at 26 weeks $(p=0.19)$. DXR-MCI reduction in the adalimumab monotherapy group was numerically lower than in the methotrexate group at 104 weeks $(\mathrm{p}=0.10)$.

\section{DXR-BMD changes between treatment arms}

The median DXR-BMD percentage changes at 26, 52 and 104 weeks were, respectively, $-1.06,-1.63$ and -2.49 in the combination group, $-0.96,-1.97$ and -2.40 for the adalimumab group and $-1.20,-1.86$ and -3.58 for the methotrexate group. The median DXR-BMD loss in the adalimumab group was numerically slightly less than in the combination group both at 26 and 104 weeks. However, the mean loss in the adalimumab group was greater at all time points (see supplementary table available online only). A significant difference between the DXR-BMD change in the methotrexate group and the combination group at 104 weeks $(p=0.049)$ was observed and a trend at 52 weeks $(p=0.10)$. A trend towards a difference between the methotrexate and adalimumab groups was observed at 104 weeks $(p=0.16)$.

Analyses on DXR-cortical thickness (DXR-CT) and DXRbone width (DXR-W) were also performed on the same subgroups that were analysed for DXR-BMD. DXR-CT showed the same pattern of bone loss as DXR-BMD and DXR-MCI. DXR-W was stable at all time points and was not influenced by treatment (see supplementary table available online only).

\section{DXR-MCI and radiographic damage}

The median (mean) radiographic changes in modified Sharp score at 26, 52 and 104 weeks, respectively, were 0 (0.5), 0 (0.9) and 0 (1.0) for the combination group, 0.5 (2.1), 0.5 (3.3) and 1.0 (4.8) for the adalimumab monotherapy group and1.0 (3.4), 2.0 (5.1) and 2.0 (6.4) for the methotrexate monotherapy group (fig 2). The discrepancy in the results of this analysis compared with findings of the original PREMIER study is probably a result of the slight differences in the number of study participants (fig 1) and the fact that no imputations were conducted in the present study. The correlations ( $\mathrm{r}$ ) between DXR-MCI change and change in Sharp score at 26, 52 and 104 weeks were $r=-0.12(p=0.001), r=-0.23(p<0.001)$ and $r=-0.32$ $(p<0.001)$. Comparable $r$ values for correlations between DXRBMD and Sharp score changes were $-0.15,-0.23$ and -0.33 , respectively $(p<0.001$ for all).
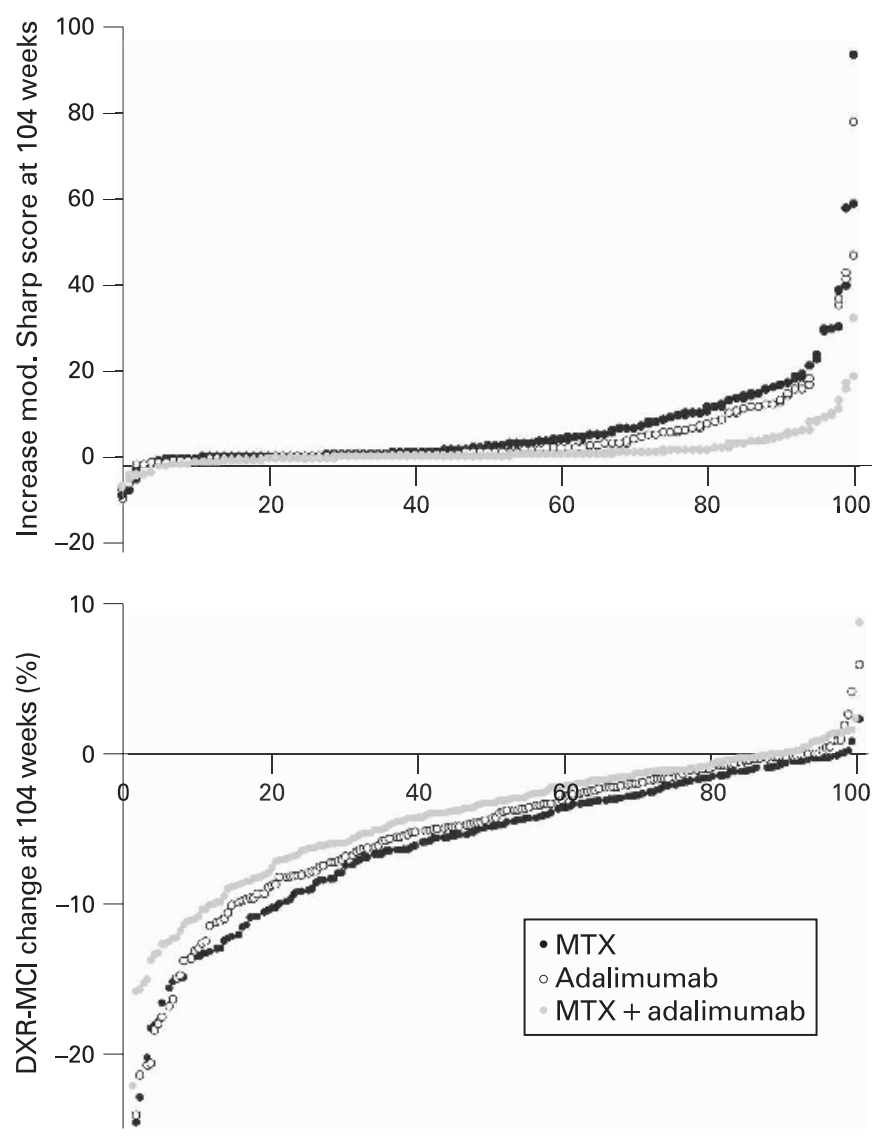

Figure 3 Cumulative probability plot: changes in DXR-MCI and radiographic scores at 104 weeks in PREMIER. DXR, digital $x$ ray radiogrammetry; $\mathrm{MCl}$, metacarpal cortical index; mod Sharp score, modified total Sharp score; MTX, methotrexate.

\section{Multivariate model}

At all time points the variables included in the final multivariate model were baseline values of disease duration, DAS28 score, CRP, DXR-MCI, HAO, radiographic damage and treatment group (dummy variable), together with age and gender.

At 52 and 104 weeks, older age, greater CRP and non-use of adalimumab turned out to be independent predictors for cortical hand bone loss. At 26 weeks, female gender and greater CRP were predictors of cortical hand bone loss. The model for 104 weeks is depicted in table 2 .

\section{DISCUSSION}

The key finding of this analysis was that anti-TNF therapy with adalimumab in combination with methotrexate provided better bone protection than either adalimumab or methotrexate monotherapies in patients with early, aggressive RA. The order of hand bone loss across the three treatment arms was the same as has been observed for overall radiographic damage in the PREMIER study (fig 2). Furthermore, the results from the multivariate model highlight the importance of inflammation (assessed with CRP) as the driving force for bone damage in active RA and the importance of TNF involvement in this process.

The present analysis adds evidence to the hypothesis that both erosions and osteoporosis are a result of the same pathophysiological mechanism, which includes activation of the osteoclast cell. This hypothesis is based on findings from both animal ${ }^{62}$ and human ${ }^{7}$ studies. 
Convincing data exist that the suppression of inflammation is important to avoid bone damage in RA. Anti-TNF therapy has in several clinical trials been shown to reduce the progression of joint erosion. ${ }^{9-11}$ Furthermore, there is also evidence that antiTNF therapy reduces osteoporosis at the hip and spine. ${ }^{412-14}$

The ability of anti-inflammatory treatment to reduce hand bone loss in RA has been demonstrated in a double-blind study comparing oral prednisolone $7.5 \mathrm{mg} /$ day for 2 years with placebo. The prednisolone group had less hand BMD loss at 1 and 2 years, suggesting that the potent anti-inflammatory effect of prednisolone exceeded its negative effect on bone. ${ }^{17}$ With respect to the effects of anti-TNF therapy on hand bone loss in RA, only a few studies have been conducted. RA patients treated with anti-TNF therapy have been shown to have a lower rate of bone loss at the spine and hip than at the hand. ${ }^{4}{ }^{14}$ In a 2-year longitudinal treatment strategy study (the BeST study), RA patients treated with anti-TNF therapy or high-dose prednisolone were shown to have a lower rate of bone loss at the hand than patients treated with conventional DMARD. ${ }^{4}$ Furthermore, in a study employing quantitative ultrasound, the use of anti-TNF therapy had a positive effect on periarticular bone. ${ }^{16}$ The beneficial effect of anti-TNF treatment on inflammatory-related hand bone loss in RA is supported by our observations.

Methotrexate has been reported to have negative effects on bone and the term "methotrexate osteopathy" has been used to describe a clinical syndrome characterised by stress fractures, diffuse bone pain and osteoporosis in children treated for malignancies. ${ }^{29}$ In animal studies high-dose methotrexate has been shown to induce apoptosis and suppress proliferation of the growth plate chondrocytes as well as proliferation of the osteoblasts and preosteoblasts. ${ }^{30}$ However, low-dose methotrexate $\left(5-20 \mathrm{mg} /\right.$ week) both in cross-sectional ${ }^{3132}$ and longitudinal $^{33}$ studies has not shown any negative effect of methotrexate on bone.

Despite the fact that bone loss was considerably lower in the combination group than in the methotrexate group, these patients were still losing hand bone. This loss may have been a result of the substantial disease activity in the PREMIER RA patients and their poor prognosis in terms of bone damage (rheumatoid factor-positive and erosive disease). ${ }^{34}$

The positive effects of anti-TNF therapy seemed to be more pronounced for radiographic joint damage than for hand bone mass (fig 2). One explanation for this may be that conventional radiographs are not sensitive enough to detect bone damage. Both ultrasound and magnetic resonance imaging (MRI) have been demonstrated to be more sensitive than radiographs in detecting erosions. ${ }^{35}$ Furthermore, MRI can detect erosions years before they become visible on radiographs ${ }^{36}$ and MRI synovitis has been detected in RA patients in both clinical and radiographic remission. ${ }^{37}$ Although MRI and ultrasound are sensitive to detect erosions, there are still some limitations for clinical use due to availability and the lack of validated scoring systems.

Hand bone loss assessed by dual $x$ ray absorptiometry has also been shown to be a more sensitive marker for bone damage than conventional radiographs. ${ }^{15}$ Therefore, the combination of everpresent inflammation in patients with greater disease activity, as well as the ability of DXR to detect small changes in bone mass, may explain the ongoing loss of hand bone. It is also important to note the influence of normal age-related bone loss that takes place in healthy adults, especially postmenopausal women. Normal bone loss for DXR-MCI has only been examined in cross-sectional studies reporting an annual rate of bone loss between $0.7 \%$ and $0.9 \% .{ }^{21} 3839$
When this analysis was planned, we intended to analyse radiographs primarily for $\mathrm{DXR}-\mathrm{BMD}$, but for reasons described in the Methods section, there were difficulties in analysing a large percentage of the radiographs for $\mathrm{DXR}-\mathrm{BMD}$. By using the relative DXR-MCI measure instead of the absolute measure of $\mathrm{BMD}$, we lost the opportunity to correct for porosity. Furthermore, DXR-BMD, as opposed to DXR-MCI, is calibrated for blurring and particular qualities of the different radiographic measurement equipment. However, DXR has improved the precision of $\mathrm{MCI}^{22}$ and there is a strong correlation between DXR-BMD and DXR-MCI $(r>0.9) .{ }^{24}{ }^{25}$ DXR-MCI and $\mathrm{DXR}-\mathrm{BMD}$ have also been found to be greatly correlated with dual $x$ ray absorptiometry-BMD ${ }^{25}$ On the basis of these facts, we believe DXR-MCI to be a valid surrogate measure of hand bone mass.

Another limitation was our inability to retrieve information on the use of bisphosphonates. This may be of importance as treatment with bisphosphonates increases bone density. For the potent bisphosphonate, zoledronic acid, the suppression of osteoclast activity has even been shown to reduce the progression of erosions both in animal ${ }^{40}$ and human ${ }^{7}$ studies. Anti-TNF therapy inhibits the osteoclast by suppressing inflammation and decreases the RANK/RANKL pathway, while the aminobisphosphonate zoledronic acid acts directly on osteoclasts. However, we believe that the study design of a double-blind, randomised controlled trial has minimised the effect of this potential bias. In addition, zoledronic acid was not on the market for osteoporosis treatment when the PREMIER study was conducted. Furthermore, in an observational study the positive effect of infliximab on bone was found to be independent of bisphosphonate use. ${ }^{12}$

In conclusion, our analysis of data from PREMIER provides evidence that potent anti-TNF therapy not only reduces the risk of developing erosions, but also reduces the rate of inflammatory-related hand bone loss in RA. This study also suggests that the bone damage disease process is still present in RA patients treated with TNF antagonists, even if radiographic joint damage on radiographs is apparently arrested. Based on the findings from the present and previous studies, quantitative measures of hand bone loss in RA patients can be recommended as outcomes for future clinical trials to detect ongoing bone damage.

Funding: Financial support was received from Abbott Laboratories.

Competing interests: MH, TKK and GH have received consulting fees as speakers from Abbott Laboratories. TKK and GH have received funding for independent research from Abbott Laboratories. AE is employed by Abbott Laboratories. JK is employed by Sectra.

Ethics approval: The PREMIER study was approved by a central institutional review board and independent ethics committees at each participating site.

\section{REFERENCES}

1. Arnett FC, Edworthy SM, Bloch DA, McShane DJ, Fries JF, Cooper NS, et al. The American Rheumatism Association 1987 revised criteria for the classification of rheumatoid arthritis. Arthritis Rheum 1988;31:315-24.

2. Haugeberg G, Green MJ, Quinn MA, Marzo-Ortega H, Proudman S, Karim Z, et al. Hand bone loss in early undifferentiated arthritis: evaluating bone mineral density loss before the development of rheumatoid arthritis. Ann Rheum Dis 2006;65:736-40.

3. Devlin J, Lilley J, Gough A, Huissoon A, Holder R, Reece R, et al. Clinical associations of dual-energy $\mathrm{X}$-ray absorptiometry measurement of hand bone mass in rheumatoid arthritis. Br J Rheumatol 1996;35:1256-62.

4. Guler-Yuksel M, Allaart CF, Goekoop-Ruiterman YP, de Vries-Bouwstra JK, van Groenendael $\mathrm{JH}$, Mallee $\mathrm{C}$, et al. Changes in hand and generalized bone mineral density in patients with recent-onset rheumatoid arthritis. Ann Rheum Dis. Published Online First 14 July 2008. doi:10.1136/ard.2007.086348.

5. Hoff M, Haugeberg G, Odegard S, Syversen S, Landewe R, van der Heijde D, et al. Cortical hand bone loss after one year in early rheumatoid arthritis predicts radiographic hand joint damage at 5 and 10 year follow-up. Ann Rheum Dis. Published Online First 13 March 2008. doi:10.1136/ard.2007.085985. 
6. Pettit AR, Ji H, von Stechow D, Muller R, Goldring SR, Choi Y, et al. TRANCE/RANKL knockout mice are protected from bone erosion in a serum transfer model of arthritis. Am J Pathol 2001;159:1689-99.

7. Jarrett SJ, Conaghan PG, Sloan VS, Papanastasiou P, Ortmann CE, O'Connor PJ, et al. Preliminary evidence for a structural benefit of the new bisphosphonate zoledronic acid in early rheumatoid arthritis. Arthritis Rheum 2006;54:1410-14.

8. Romas $\mathbf{E}$, Gillespie MT. Inflammation-induced bone loss: can it be prevented? Rheum Dis Clin North Am 2006; 32:759-73.

9. St Clair EW, van der Heijde DM, Smolen JS, Maini RN, Bathon JM, Emery P, et al. Combination of infliximab and methotrexate therapy for early rheumatoid arthritis: a randomized, controlled trial. Arthritis Rheum 2004;50:3432-43.

10. van der Heijde DM, Klareskog L, Rodriguez-Valverde V, Codreanu C, Bolosiu H, Melo-Gomes J, et al. Comparison of etanercept and methotrexate, alone and combined, in the treatment of rheumatoid arthritis: two-year clinical and radiographic results from the TEMPO study, a double-blind, randomized trial. Arthritis Rheum 2006;54:1063-74.

11. Breedveld FC, Weisman MH, Kavanaugh AF, Cohen SB, Pavelka K, van Vollenhoven $\mathrm{R}$, et al. The PREMIER study: a multicenter, randomized, double-blind clinical trial of combination therapy with adalimumab plus methotrexate versus methotrexate alone or adalimumab alone in patients with early, aggressive rheumatoid arthritis who had not had previous methotrexate treatment. Arthritis Rheum 2006;54:26-37.

12. Marotte H, Pallot-Prades B, Grange L, Gaudin P, Alexandre C, Miossec P. A 1-year case-control study in patients with rheumatoid arthritis indicates prevention of loss of bone mineral density in both responders and nonresponders to infliximab. Arthritis Res Ther 2007; $9:$ :R61.

13. Lange U, Teichmann J, Muller-Ladner U, Strunk J. Increase in bone mineral density of patients with rheumatoid arthritis treated with anti-TNF-alpha antibody: a prospective open-label pilot study. Rheumatology (Oxford) 2005;44:1546-8.

14. Vis M, Havaardsholm EA, Haugeberg G, Uhlig T, Voskuyl AE, van der Stadt RJ, et al. Evaluation of bone mineral density, bone metabolism, osteoprotegerin and receptor activator of the NFkappaB ligand serum levels during treatment with infliximab in patients with rheumatoid arthritis. Ann Rheum Dis 2006;65:1495-9.

15. Haugeberg G, Green MJ, Conaghan PG, Quinn M, Wakefield R, Proudman SM, et al. Hand bone densitometry: a more sensitive standard for the assessment of early bone damage in rheumatoid arthritis. Ann Rheum Dis 2007;66:1513-17.

16. Seriolo B, Paolino S, Sulli A, Ferretti V, Cutolo M. Bone metabolism changes during anti-TNF-alpha therapy in patients with active rheumatoid arthritis. Ann NY Acad Sci 2006;1069:420-7.

17. Haugeberg G, Strand A, Kvien TK, Kirwan JR. Reduced loss of hand bone density with prednisolone in early rheumatoid arthritis: results from a randomized placebocontrolled trial. Arch Intern Med 2005;165:1293-7.

18. Barnett $\mathbf{E}$, Nordin BE. The radiological diagnosis of osteoporosis: a new approach Clin Radiol 1960;11:166-74.

19. Rosholm A, Hyldstrup L, Backsgaard L, Grunkin M, Thodberg HH. Estimation of bone mineral density by digital X-ray radiogrammetry: theoretical background and clinical testing. Osteoporos Int 2001;12:961-9.

20. Jorgensen JT, Andersen PB, Rosholm A, Bjarnason NH. Digital X-ray radiogrammetry: a new appendicular bone densitometric method with high precision. Clin Physiol 2000;20:330-5.

21. Hyldstrup L, Nielsen SP. Metacarpal index by digital X-ray radiogrammetry: normative reference values and comparison with dual X-ray absorptiometry. J Clin Densitom 2001;4:299-306.

22. Nielsen SP. The metacarpal index revisited: a brief overview. J Clin Densitom 2001:4:199-207.
23. Hoff M, Dhainaut A, Kvien TK, Haugeberg G. Short time precision assessed with digital $\mathrm{X}$-ray radiogrammetry in healthy individuals and rheumatoid arthritis patients [abstract.] Ann Rheum Dis 2008;67(suppl 2):563.

24. Bottcher J, Malich A, Pfeil A, Petrovitch A, Lehmann G, Heyne JP, et al. Potentia clinical relevance of digital radiogrammetry for quantification of periarticular bone demineralization in patients suffering from rheumatoid arthritis depending on severity and compared with DXA. Eur Radiol 2004;14:631-7.

25. Hoff M, Haugeberg G, Kvien TK. Hand bone loss as an outcome measure in established rheumatoid arthritis: 2-year observational study comparing cortical and total bone loss. Arthritis Res Ther 2007; 9:R81.

26. Prevoo ML, van't Hof MA, Kuper HH, van Leeuwen MA, van de Putte LB, van Riel PL. Modified disease activity scores that include twenty-eight-joint counts. Development and validation in a prospective longitudinal study of patients with rheumatoid arthritis. Arthritis Rheum 1995;38:44-8.

27. Fries JF, Spitz P, Kraines RG, Holman HR. Measurement of patient outcome in arthritis. Arthritis Rheum 1980;23:137-45.

28. Redlich K, Hayer S, Ricci R, David JP, Tohidast-Akrad M, Kollias G, et al. Osteoclasts are essential for TNF-alpha-mediated joint destruction. J Clin Invest 2002;110:1419-27.

29. Schwartz AM, Leonidas JC. Methotrexate osteopathy. Skeletal Radiol 1984;11:13-16.

30. Xian CJ, Cool JC, Scherer MA, Macsai CE, Fan C, Covino M, et al. Cellular mechanisms for methotrexate chemotherapy-induced bone growth defects. Bone 2007:41:842-50.

31. di Munno 0, Mazzantini M, Sinigaglia L, Bianchi G, Minisola Gmuratore M, et al. Effect of low dose methotrexate on bone density in women with rheumatoid arthritis: results from a multicenter cross-sectional study. J Rheumatol 2004;31:1305-9.

32. Cranney AB, McKendry RJ, Wells GA, Ooi DS, Kanigsberg ND, Kraag GR, et al The effect of low dose methotrexate on bone density. J Rheumatol 2001;28:2395-9.

33. Minaur NJ, Kounali D, Vedi S, Compston JE, Beresford JN, Bhalla AK. Methotrexate in the treatment of rheumatoid arthritis. II. In vivo effects on bone mineral density. Rheumatology (Oxford) 2002;41:741-9.

34. Emery P. The Dunlop-Dottridge Lecture: prognosis in inflammatory arthritis: the value of HLA genotyping and the oncological analogy. J Rheumatol 1997;24:1436-42.

35. Dohn UM, Ejbjerg BJ, Court-Payen, Hasselquist M, Narvestad E, Szkularek M, et al Are bone erosions detected by magnetic resonance imaging and ultrasonography true erosions? A comparison with computed tomography in rheumatoid arthritis metacarpophalangeal joints. Arthritis Res Ther 2006:8:R110.

36. Ostergaard M, Hansen M, Stoltenberg M, Jensen KE, Szkudlarek M, PedersenZbinden $\mathrm{B}$, et al. New radiographic bone erosions in the wrists of patients with rheumatoid arthritis are detectable with magnetic resonance imaging a median of two years earlier. Arthritis Rheum 2003;48:2128-31.

37. Brown AK, Quinn MA, Karim Z, Conaghan PG, Peterfy CG, Hensor E, et al. Presence of significant synovitis in rheumatoid arthritis patients with disease-modifying antirheumatic drug-induced clinical remission: evidence from an imaging study may explain structural progression. Arthritis Rheum 2006:54:3761-73.

38. Bottcher J, Pfeil A, Schafer ML, Petrovitch A, Seidl BE, Mentzel HJ, et al. Normative data for digital X-ray radiogrammetry from a female and male German cohort. J Clin Densitom 2006:9:341-50.

39. Toledo VA, Jergas M. Age-related changes in cortical bone mass: data from a German female cohort. Eur Radiol 2006;16:811-17.

40. Herrak P, Gortz B, Hayer S, Redlich K, Reiter E, Gasser J, et al. Zoledronic acid protects against local and systemic bone loss in tumor necrosis factor-mediated arthritis. Arthritis Rheum 2004:50:2327-37. 